\title{
Erratum to: Renal impairment in children with posterior urethral valves
}

\author{
Jameela Abdulaziz Kari • Sherif El-Desoky • Youssef M. K. Farag • Hisham Mosli • \\ Abdul-Malik Altyieb • Ahmad Al Sayad • Othman Radawi • Hosam Ghabra • \\ Faten Basnawi • Ohood Bahrawi • Ajay Singh • Hassan Farsi
}

Published online: 29 March 2014

(C) IPNA 2014

\section{Erratum to: Pediatr Nephrol}

DOI 10.1007/s00467-012-2390-7

The name of the third author was rendered incorrectly. The correct name is Youssef M.K. Farag.

The online version of the original article can be found under doi:10.1007/ s00467-012-2390-7.

J. A. Kari $(\bowtie) \cdot$ S. El-Desoky $\cdot$ O. Radawi $\cdot$ H. Ghabra •

F. Basnawi $\cdot$ O. Bahrawi

Department of Pediatrics, Faculty of Medicine, King Abdulaziz

University, PO Box 80215, Jeddah 21589, Kingdom of Saudi Arabia

e-mail: jkari@doctors.org.uk

Y. M. K. Farag $\cdot$ A. Singh

Renal Division, Brigham and Women's Hospital, Harvard Medical

School, Boston, MA, USA

Y. M. K. Farag $\cdot$ A. Singh

Johns Hopkins Bloomberg School of Public Health, Baltimore, MD,

USA

H. Mosli • A.-M. Altyieb · A. Al Sayad · H. Farsi

Department of Urology, Faculty of Medicine, King Abdulaziz

University, Jeddah, Kingdom of Saudi Arabia 